\title{
Addressing the diverging public and physician perceptions on the topic of antibiotic resistance
}

\section{A review of current progress and future directions}

\author{
Hong Yu Su, Matt Douglas-Vail \\ Faculty Reviewer: Sameer Elsayed, MD, FRCC (Department of Medicine; Department of Pathology and Laboratory Medicine; Divi- \\ sion of Infectious Diseases; Division of Microbiology)
}

\section{ABSTRACT}

Antibiotics are a powerful tool in fighting bacterial infections but with overuse and misuse, resistance is emerging at an alarming rate. To better understand the root causes of resistance, studying the perceptions of both physicians and the general populace may prove beneficial from a health promotion standpoint. Research reveals that diverging views of these 2 groups remain significant, which proves concerning especially in the face of increasingly resistant bacteria and associated mortality. The issue at large, therefore, requires a better understanding from both parties with regard to antibiotic guidelines, prescription habits and public awareness campaigns.

\section{INTRODUCTION}

The world we live in today is built, in part, upon the shoulders of antibiotics. They represent our strongest tool against bacterial infections and are arguably one of the greatest successes in public health. However, exploitation of this valuable resource has led to an uphill battle in the quest for new antibiotics since the 1960s. ${ }^{1}$ At this rate, a world in which lethal bacterial infections are the norm may once more become a grim reality. According to the US Centre for Disease Control and Prevention (CDC), in 2013 alone, roughly 2 million people fell victim to highly resistant bacteria, which subsequently led to over 23000 casualties. $^{2}$

As indicated by the Government of Canada, some of the currently rampant drug resistant bacteria include multidrug-resistant (MDR) Escherichia coli, vancomycin-resistant enterococci (VRE) and methicillin-resistant Staphylococcus aureus (MRSA). ${ }^{3}$ Some of the statistics also proved worrying-for instance, rates of gonorrhea infection have been steadily climbing since the late 1990s, coupled with the emergence of multidrug-resistant strains that present significant therapeutic challenges. ${ }^{3}$ At the same time, resistant Salmonella accounted for 759 of the 2987 total Salmonella reports in $2013,{ }^{4}$ more than a quarter of all cases.

Not surprisingly, antibiotic resistance is currently an urgent concern to Canadian healthcare providers. The issue at hand is intricately complex and requires in-depth understanding of both public perception as well as approaches aimed at increasing public awareness, both of which will be addressed in greater detail in subsequent sections.

\section{PUBLIC PERCEPTIONS OF ANTIBIOTIC RESISTANCE: THE PATIENT AND PHYSICIAN PERSPECTIVES}

A greater understanding of laypeople's perceptions may offer significant insights into determinants of misuse, as proposed by numerous epidemiological studies. ${ }^{5}$ A large study conducted in the early 2000 s $(n=5379)$ revealed that as many as $11 \%$ resorted to overstating their clinical symptoms in order to get an antibiotic prescription from their physicians. According to Haynes et al, there also seems to be confusion among the general public regarding the specific therapeutic indications for antibiotics, as their studies show that the majority consider antibiotics to be effective in the context of common colds, with $79 \%$ of patients reporting utilization when "discolored nasal discharge" was present $(\mathrm{P}=0.001) .{ }^{5}$ Meanwhile, those who display avid aversions to antibiotic usage seem to do so for the wrong reasons. Based on another study more centered on narratives, many of those interviewed showed reluctance because antibiotics "upset the body somehow," and others admit to being common users of alternative medicine such as homeopathy, believing that antibiotics are the cause of increasing incidences of illnesses in the current generation. ${ }^{6}$

Furthermore, there are also studies that seek to understand exactly how patients interpret the term antibiotic resistance. A survey conducted in 9 countries across Europe $(n=121)$ found that virtually all patients associated resistance with antibiotic use, but not to a point deemed to be considered an "accepted scientific view." Instead, most (median 88\% [interquartile range (IQR) 86\%-89\%], $\mathrm{n}=2$ studies) resort to the vague concept of resistant body for their explanations and were incapable of explaining antibiotic resistance in any greater detail. Another significant percentage (median 70\% [IQR 59-77\%], $\mathrm{n}=11$ studies) believed that excessive use and failure to complete treatment courses are the drivers of resistance. ${ }^{7}$ From their perspective, antibiotic resistance develops not due to mutations in bacteria but the human body gradually mounting tolerance, meaning every antibiotic can only be used for a limited time period before it becomes obsolete. The above observations have been replicated in many other studies as well, ${ }^{8-10}$ suggesting that we are still far from reaching an adequate understanding in the general populace, and initiatives designed to raise greater awareness in this subject area should be more extensively implemented and promoted.

It is also noteworthy to address the two-sided nature of this issue. Patients aside, a meta-analysis conducted this year suggests 
physicians also played a significant role in exacerbating the situation. A systematic review of 57 studies involving over 11000 physicians, mostly across North America, show that while most admit to being aware of antibiotic resistance as a serious global health issue, a significant number of respondents also designated short treatment courses, low dosage and patient noncompliance as contributing factors. ${ }^{11}$ This shows evidence for diffusion of responsibility amongst physicians, and suggests that in order for the concern to be properly addressed in the foreseeable future, the combined contributions from both the patients and physicians are required.

\section{ADDRESSING THE ISSUE: WHAT CAN BE DONE TO INFLUENCE PUBLIC PERCEPTIONS}

A number of measures have been suggested by the Canadian Government to combat this trend, keeping in mind that both Canadians and healthcare professionals alike should play their part. Some general recommendations include maintaining good hygiene, ensuring proper sneezing methods to prevent bacterial host transfer, practicing safer sex and keeping up with current vaccinations. Physicians and other healthcare professionals share the added responsibility of preventing the spread through suboptimal dispensing practices. Whenever possible, antibiotic stewardship should be employed and clinical practice guidelines should be strictly adhered to. ${ }^{12}$ The World Health Organization (WHO) also publishes its own sets of standards regarding approaches to control antimicrobial resistance. It implements many surveillance programs, such as the Global Antimicrobial Resistance Surveillance System (GLASS), that provide an internationally standardized approach for collecting relevant data on the most resistance-prone bacterial species worldwide, ${ }^{13}$ making it much easier to track resistance progress. Finally, they publish reports that outline practical guidelines such as rational drug use, which physicians can access and consult either for their own professional development or for promoting these practices in the community at large.

Historical polling reveals that while public faith in the healthcare system has significantly fluctuated over time (as low as $23 \%$ in 2014), trust and confidence in the physicians' knowledge and personal values has remained overwhelmingly positive. ${ }^{14}$ It is no surprise therefore that respondents in a randomized survey admitted that if a physician prescribed them antibiotics for a certain condition, they would be much more inclined to request antibiotics when the same condition re-emerges, irrespective of the actual nature of the condition. ${ }^{15}$ Consequently, physician prescribing habits are a key element in the containment of excessive antibiotics use, and they should be the first subpopulation targeted for appropriate education and should also be encouraged to self-educate in this subject area.

It is also interesting to point out that those with a greater educational background were no less likely to be prescribed antibiotics, and individuals with higher perceived knowledge about antibiotics were in fact more likely to self-medicate and keep leftover antibiotics. ${ }^{15}$ The implications of this finding are not entirely clear, but does seem to suggest that changing physician and public perceptions alone is by no means an exhaustive approach to combat antibiotic resistance. The overarching scheme should be multidisciplinary in nature and include a combination of epidemiological studies, population surveys, pharmaceutical research, dispensing practices by health professionals and government intervention (eg, limiting antibiotics use by placing quotas).

Meanwhile, for the lay public, raising awareness should be much less resource-intensive and should instead take the form of public health campaigns. Campaigns have often been an effective medium to relay important messages. For instance, there are currently many campaigns directed at raising awareness about the various cancer screening programs such as colorectal cancer, as demonstrated by the Canadian Cancer Society. ${ }^{16}$ An article published in the UK reported that a pilot colorectal cancer screening awareness campaign resulted in a $10 \%$ increase in participation within a single month. ${ }^{17}$ Greater emphasis should also be placed on educating the public on the importance of their own contributions. A large portion of the public consider their role in antibiotic resistance to be minimal, and believe the root of resistance lies with unsanitary hospitals. Many also resort to popular media as their primary source of information on these topics. ${ }^{18}$ One way to approach this would be to urge patients to acquire their information from more reputable sources, and assist them in the process by providing examples of databases known to contain more reliable information. The alternative would be to actually harness the power of the media, and generate campaigns compatible with multiple media sources so that they are more widely received by the public.

\section{CONCLUSION}

Our paper discussed antibiotics resistance as one of the forefront concerns in healthcare, one that is bound to be exacerbated if the government, physicians and the public fail to react promptly and implement appropriate strategies. The current landscape is deteriorating rapidly as spine-chilling cases of resistant bacteria, with the potential to kill many millions, make routine headlines. ${ }^{19}$ Improving physician and patient understanding of the underlying basis of antimicrobial resistance currently takes precedence, but a truly multidisciplinary strategy is required to pave the way for a new era, where antibiotics can once more be the symbol of a successful public health story, for now and for many years to come.

\section{REFERENCES}

1. Lewis K. Recover the lost art of drug discovery: bacterial evolution is overwhelming our antibiotic defences. Nature. 2012 May 24;485(7399):439-40.

2. Frieden T. Antibiotic resistance threats in the United States, 2013. Atlanta (GA): Centers for Disease Control and Prevention (US); 2014 Jul. 113p. Report No.: CS239559-B.

3. Antibiotic-resistant illnesses and bacteria [Internet]. Centre for Communicable Diseases and Infection Control. 2014 July 10 [updated 2015 Aug 21; cited 2015 Nov 9]. Available from: http://healthycanadians. gc.ca/drugs-products-medicaments-produits/buying-using-achat-utilisation/antibiotic-resistance-antibiotique/illnesses-maladies-eng.php

4. Canadian antimicrobial resistance surveillance system report 2015. Ottawa (ON): Centre for Communicable Diseases and Infection Control. 2014 Jul. 53p. Catalogue No.: HP37-21E-PDF.

5. Pechere JC. Patients' interviews and misuse of antibiotics. Clin Infect Dis. 2011 Sep 15;33(S3): S170-3. 


\section{HEALTH PROMOTION}

6. Mainous III AG, Zoorob RJ, Oler MJ, Haynes DM. Patient knowledge of upper respiratory infections: implications for antibiotic expectations and unnecessary utilization. J Fam Practice. 1997 July;45(1):7583.

7. Brookes-Howell L, Elwyn G, Hood K, Wood F, Cooper L, Goossens H, et al. 'The body gets used to them': patients' interpretations of antibiotic resistance and the implication of containment strategies. J Gen Intern Med. 2011 Nov 8;27(7):766-72.

8. Fredericks I, Hollingworth S, Pudmenzky A, Rosato L, Syed S, Kairuz T. Consumer knowledge and perceptions about antibiotics and upper respiratory infections in a community pharmacy. Int J Clin Pharm. 2015 Sep 21;37(6):1213-21.

9. Wiklund S, Fagerberg I, Ortgvist A, Vading M, Giske CG, Broliden K, et al. Knowledge and understanding of antibiotic resistance and the risk of becoming a carrier when travelling abroad: a qualitative study of Swedish travellers. Scan J Public Health. 2015 Feb 23;43(3):302-8.

10. Gualano MR, Gili R, Scaioli G, Bert F, Siliguini R. General population's knowledge and attitudes about antibiotics: a systematic review and meta-analysis. Pharmacoepidemiol Drug Saf. 2014 Sep 24;24(1):2-10.

11. McCullough AR, Rathbone J, Parekh S, Hoffmann TC, Del Marr CB. Not in my backyard: a systematic review of clinicians' knowledge and beliefs about antibiotic resistance. J Antimicrob Chemother. 2015 June 20;70(9):2465-73.

12. Prevention of antibiotic resistance [Internet]. Centre for Communicable Diseases and Infection Control. 2014 Sep 30 [cited 2015 Nov 9]. Available from: http://healthycanadians.gc.ca/drugs-products-medicaments-produits/buying-using-achat-utilisation/antibiotic-resistance-antibiotique/prevention-eng.php

13. Antimicrobial use [Internet]. World Health Organization. 2015 [cited 2015 Oct 25]. Available from: http://www.who.int/drugresistance/use/ en/.

14. Blendon RJ, Benson JM, Hero JO. Public trust in physicians - US medicine in international perspective. N Engl J Med. 2014 Oct 23;371(17):1570-2.

15. McNulty CA, Boyle P, Nichols T, Clappison P, Davey P. The public's attitudes to and compliance with antibiotics. J Antimicrob Chemother. 2007 Aug;60(1):i63-8.

16. Screening of colorectal cancer [Internet]. Canadian Cancer Society. 2015 [cited 2015 Nov 4]. Available from: http://www.cancer.ca/en/ prevention-and-screening/early-detection-and-screening/screening/ screening-for-colorectal-cancer/?region=pe.

17. Whyte S, Harnan S. Effectiveness and cost-effectiveness of an awareness campaign for colorectal cancer: a mathematical modeling study. Cancer Causes Control. 2014 Mar 29;25(6):647-58.

18. Hawkings NJ, Wood F, Butler CC. Public attitudes towards bacterial resistance: a qualitative study. J Antimicrob Chemother. 2007 Apr 21;59(6):1155-60.

19. Lauren W. This disease could kill 75 million people by 2050 [Internet]. The Huffington Post. 2015 Oct 23 [cited 2015 Nov 4]. Available from: http://www.huffingtonpost.com/entry/tuberculosis-mdr-tb-treatment_56211f2be4b06462al3bc8fd. 